Medicine, The University of Tokyo, 7-3-1 Hongo, Bunkyo-ku, Tokyo 113-0033, Japan. Phone: 81.3.5841.3431; Fax: 81.3.5841.3393; E-mail: koujim@m.u-tokyo.ac.jp.

1. Covacci A, Telford JL, Del Giudice G, Parsonnet J, Rappuoli R. Helicobacter pylori virulence and genetic geography. Science. 1999;284(5418):1328-1333.

2. Blaser MJ. An endangered species in the stomach. Sci Am. 2005;292(2):38-45.

3. Marshall BJ, Warren JR. Unidentified curved bacilli in the stomach of patients with gastritis and peptic ulceration. Lancet. 1984;1(8390):1311-1315

4. Superbaum S, Michetti P. Helicobacter pylori infection. N Engl J Med. 2002;347(15):1175-1186.

5. Chen Y, Blaser MJ. Inverse associations of Helicobacter pylori with asthma and allergy. Arch Intern Med. 2007;167(8):821-827.

6. Strachan DP. Hay fever, hygiene, and household size. BMJ. 1989;299(6710):1259-1260.

7. Arnold IC, et al. Helicobacter pylori infection prevents allergic asthma in mouse models through the induction of regulatory $\mathrm{T}$ cells. J Clin Invest.
2011;121(8):3088-3093

8. Oertli M, et al. DC-derived IL-18 drives Treg differentiation, murine Helicobacter pylori-specific immune tolerance, and asthma protection. J Clin Invest. 2012;122(3):1082-1096.

9. Steinman RM, Cohn ZA. Identification of a novel cell type in peripheral lymphoid organs of mice. I. Morphology, quantitation, tissue distribution. J Exp Med. 1973;137(5):1142-1162.

10. Maldonado RA, von Andrian UH. How tolerogenic dendritic cells induce regulatory T cells. Adv Immunol. 2010;108:111-165.

11. Watanabe T, et al. NOD1 contributes to mouse host defense against Helicobacter pylori via induction of type I IFN and activation of the ISGF3 signaling pathway. J Clin Invest. 2010;120(5):1645-1662.

12. Gu Y, et al. Activation of Interferon-gamma inducing factor mediated by Interleukin-1beta converting enzyme. Science. 1997;275(5297):206-209.

13. Yoshimoto T, et al. Nonredundant roles for CD1drestricted natural killer $\mathrm{T}$ cells and conventional CD4+ $\mathrm{T}$ cells in the induction of immunoglobulin $\mathrm{E}$ antibodies in response to interleukin 18 treatment of mice. J Exp Med. 2003;197(8):997-1005

14. Koch MA, Tucker-Heard G, Perdue NR, Killebrew
JR, Urdahl KB, Campbell DJ. The transcription factor T-bet controls regulatory $\mathrm{T}$ cell homeostasis and function during type 1 inflammation. Nat Immunol. 2009;10(6):595-602.

15. Zheng Y, et al. Regulatory T-cell suppressor program co-opts transcription factor IRF-4 to control Th2 responses. Nature. 2009;458(7236):351-356.

16. Sakaguchi S, Yamaguchi T, Nomura T, Ono M. Regulatory T cells and immune tolerance. Cell. 2008; 133(5):775-787.

17. Schreiber S, et al. The spatial orientation of Helicobacter pylori in the gastric mucus. Proc Natl Acad Sci US A. 2004;101(14):5024-5029.

18. Petersen AM, Krogfelt KA. Helicobacter pylori: an invading microorganism? A review. FEMS Immunol Med Microbiol. 2003;36(3):117-126.

19. Ito T, et al. Helicobacter pylori invades the gastric mucosa and translocates to the gastric lymph nodes. Lab Invest. 2008;88(6):664-681.

20. Nagai S, et al. Role of Peyer's patches in the induction of Helicobacter pylori-induced gastritis. Proc Natl Acad Sci U S A. 2007;104(21):8971-8976.

21. Kiriya K, et al. Essential role of Peyer's patches in the development of Helicobacter-induced gastritis. Int Immunol. 2007;19(4):435-446.

\title{
NPs - heart hormones that regulate brown fat?
}

\author{
Andrew J. Whittle and Antonio Vidal-Puig
}

University of Cambridge Metabolic Research Laboratories, Institute of Metabolic Science, Cambridge, United Kingdom.

\begin{abstract}
Thermogenesis in brown adipose tissue (BAT) is well characterized as being under the control of the sympathetic nervous system. The energy-burning capacity of BAT makes it an attractive target for anti-obesity therapies. However, previous attempts to manipulate BAT's sympathetic activation have lacked specificity. In this issue of the JCI, Bordicchia et al. provide new data indicating that cardiac natriuretic peptides (NPs) are also able to activate thermogenic machinery in adipose tissue. Their findings suggest a novel strategy to increase energy dissipation in adipose tissue, independent of adrenergic receptors.
\end{abstract}

\section{Regulation of the thermogenic program via p38 MAPK}

Obesity is a growing epidemic that places an impossible burden on the health care systems of both developed and developing countries across the globe, due to the negative effects of excess fat accumulation on multiple organs. Fat is stored mainly in the well-described white adipose tissue (WAT), but there exists a second fat reservoir known as brown adipose tissue (BAT). Maintenance of core body temperature is essential to all mammals, and brown fat is highly specialized to generate heat. In smaller organisms such as rodents, it is well established that brown adipocytes perform

Conflict of interest: The authors have declared that no conflict of interest exists.

Citation for this article: J Clin Invest. 2012; 122(3):804-807. doi:10.1172/JCI62595. an essential role in this process, and there is now substantial evidence that BAT depots exist and are active in adult humans (1-3). Following exposure to cold temperatures, the brain coordinates increased activation of BAT via the sympathetic nervous system (SNS). Brown adipocytes in BAT and populations of "brown-like" adipocytes in WAT respond by increasing transcription of genes important for mobilizing and oxidizing lipids to generate heat. This genetic response is known as the thermogenic program, the key components of which are lipases and the specialized mitochondrial transporter uncoupling protein 1 (UCP1). UCP1 enables the separation of lipid oxidation from ATP production, allowing a higher metabolic rate and the conversion of nutritional energy to heat (4). Understanding the regulation of the thermogenic program is of particular importance, as its induction is fundamental to not just thermogenic activity but also the differentiation of adipocytes toward a more "brown" cell fate (5). In this issue of the JCI, Bordicchia, Collins, and colleagues demonstrate a novel mechanism for activating this genetic program in adipose tissue (6).

Adrenergic signaling is the classical activator of the thermogenic machinery. Catecholamines drive increased intracellular cAMP levels, directly activating cAMP-dependant protein kinase (PKA), which subsequently phosphorylates hormone-sensitive lipase (HSL). But as shown previously by the Collins team, PKA can also phosphorylate kinases in the p38 MAPK pathway $(7,8)$. The UCP1 promoter contains motifs bound by multiple transcription factors, such as activating transcription factor-2/cAMP response element-binding (ATF2/CREB) and PPAR $\gamma$, the transcriptional effects of which are all enhanced by increased p38 MAPK activation. Pharmacological inhibition of p38 MAPK is sufficient to negate the effects of adrenergic stimulation on UCP1 transcription (7).

Previous strategies aimed at increasing energy dissipation in BAT through enhanced activation of the adrenergic system have proved successful at reduc- 


\section{Table 1}

Non-adrenergic activators of the thermogenic program

\begin{tabular}{|c|c|c|c|}
\hline Molecule & Mechanism & Effects & Ref. \\
\hline FGF21 & $\begin{array}{l}\text { Secretory protein expressed in liver and BAT. } \\
\text { Signals through the } \beta \text {-klotho receptor. }\end{array}$ & $\begin{array}{l}\text { Treatment of mice with FGF21 induces the thermogenic program } \\
\text { in BAT, elevating oxygen consumption via increased coupling. }\end{array}$ & 14 \\
\hline Orexin & $\begin{array}{l}\text { Produced in the brain and potentially the } \\
\text { pancreas. Signals through BMPR1A to } \\
\text { increase p38 MAPK activation. }\end{array}$ & $\begin{array}{l}\text { Required for the development of BAT in mice in vivo. Treatment } \\
\text { of preadipocytes with orexin drives expression of } \\
\text { thermogenic genes. }\end{array}$ & 16 \\
\hline BMP7 & $\begin{array}{l}\text { Secretory protein expressed in preadipocytes. } \\
\text { Signals through Smads and activates p38 } \\
\text { MAPK and ATF2 in brown adipocytes. }\end{array}$ & $\begin{array}{l}\text { Required for the development of BAT in mice in vivo. Treatment } \\
\text { of young mice leads to enhanced brown adipogenesis } \\
\text { and mitochondriogenesis. }\end{array}$ & 17 \\
\hline ANP/BNP & $\begin{array}{l}\text { Hemodynamic hormones secreted by the heart. } \\
\text { Signal through PKG to activate p38 MAPK. }\end{array}$ & $\begin{array}{l}\text { Treatment of human adipocytes with ANP increases mitochondrial } \\
\text { uncoupling and thermogenic gene expression. BNP infusion } \\
\text { in mice drives the thermogenic program in BAT and WAT and } \\
\text { increases energy expenditure. }\end{array}$ & 6 \\
\hline Bile acids & $\begin{array}{l}\text { Steroid acids produced in the liver. Signal } \\
\text { through GPCRs to interact with thyroid } \\
\text { signaling and activate MAPK pathways. }\end{array}$ & $\begin{array}{l}\text { Bile acid treatment of mice protects against obesity by increasing } \\
\text { energy expenditure in BAT. Treatment of brown adipocytes } \\
\text { increases thyroid action and metabolic activity. }\end{array}$ & 18 \\
\hline Nitric oxide & $\begin{array}{l}\text { Diffuses freely across cell membranes. } \\
\text { Increases cyclic GMP levels. }\end{array}$ & $\begin{array}{l}\text { Mice treated with nitric oxide precursors have improved BAT } \\
\text { expansion and thermogenic gene expression in response } \\
\text { to cold exposure. }\end{array}$ & 19 \\
\hline
\end{tabular}

ing body weight in overweight individuals $(9,10)$. However, the effective compounds (ephedrine and sibutramine) have also been found to significantly increase the risk of heart attack and stroke, particularly in obese patients $(11,12)$. This is largely attributed to the widespread expression of adrenergic receptors throughout the cardiovascular system and the indiscriminate manner in which these compounds act upon them.

\section{Cardiac natriuretic peptides activate thermogenesis}

Natriuretic peptides (NPs) are hormones produced in the heart that traditionally act on the renal system to maintain fluid homeostasis and exist in atrial (ANP) and ventricular (BNP) forms. They signal through an active receptor (NPRA) and a clearance receptor (NPRC), with the regulation of both modulating NP activity. Interestingly, NPs increase cyclic GMP levels to activate cGMP-dependant protein kinase (PKG), which shares homology with PKA in terms of its potential substrates (13). Bordicchia et al. provide evidence that in addition to regulating hemodynamics, NP signaling is also an important part of the thermogenic response in adipocytes (6).

The authors begin by demonstrating that mice lacking NPRC - the negative regulator of NP activity - have reduced fat deposition in WAT and less lipid accumulation in BAT, perhaps suggesting increased thermogenic activity. NPRC-null mice also possess inguinal WAT that displays a more "brown-like" morphology and have increased expression of thermogenic genes in both WAT and BAT. Using a human-derived adipocyte cell line, the authors proceed to show that treatment with ANP results in induction of thermogenic and mitochondrial genes and that these increases are dependent on PKG signaling. At a functional level, these transcriptional changes induced by ANP increase the capacity for uncoupled respiration in acutely treated adipocytes. This effect appears more potent following a longer pretreatment, suggesting chronically increased ANP signaling may bring about adaptive changes in BAT (6).

Bordicchia et al. progress to show that NPs elicit this response by increasing p38 MAPK signaling and phosphorylation of ATF2, directly increasing UCP1 transcription in adipocytes. The effects of ANP on transcription of UCP1 and indeed other thermogenic genes appear to be additive to, and perhaps synergistic with, those increases seen following classical adrenergic stimulation. Compared with physiological stimulation, the response to the relatively high dose of agonist used in the studies (10 nM isoproterenol) demonstrates a second important characteristic of adipocytes: that there is room for further amplification of the thermogenic machinery above the level resulting from a potent adrenergic stimulus, and this can be induced using NPs. Finally, the authors add support to this hypothesis by treating mice with BNP and observing an increase in energy expenditure accompanied by increased thermogenic protein levels in both BAT and WAT (6).

\section{An increasing pool of novel BAT activators}

These new findings provide further support for the hypothesis that there are additional mechanisms for activating thermogenesis in BAT that sidestep the need for manipulating the SNS. NPs appear to provide an opportunity to increase the scale of the thermogenic response in BAT and WAT without altering endogenous adrenergic stimulation.

Over the past five years, a number of molecules have also been shown to possess thermogenic properties not reliant on adrenergic receptors (Table 1 ). In a remarkably similar fashion to NP, fibroblast growth factor 21 (FGF21) has been found to induce thermogenic program genes and increase uncoupled respiration in brown adipocytes via the $\beta$-klotho receptor (14, 15). Orexins have been demonstrated to signal through bone morphogenetic protein receptor-1a (BMPR1A) and, like NP, feed into the p38 MAPK pathway to induce thermogenic genes and drive brown adipogenesis (16). One bone morphogenetic protein (BMP7) itself has also been shown to stimulate a similar "browning" effect in 


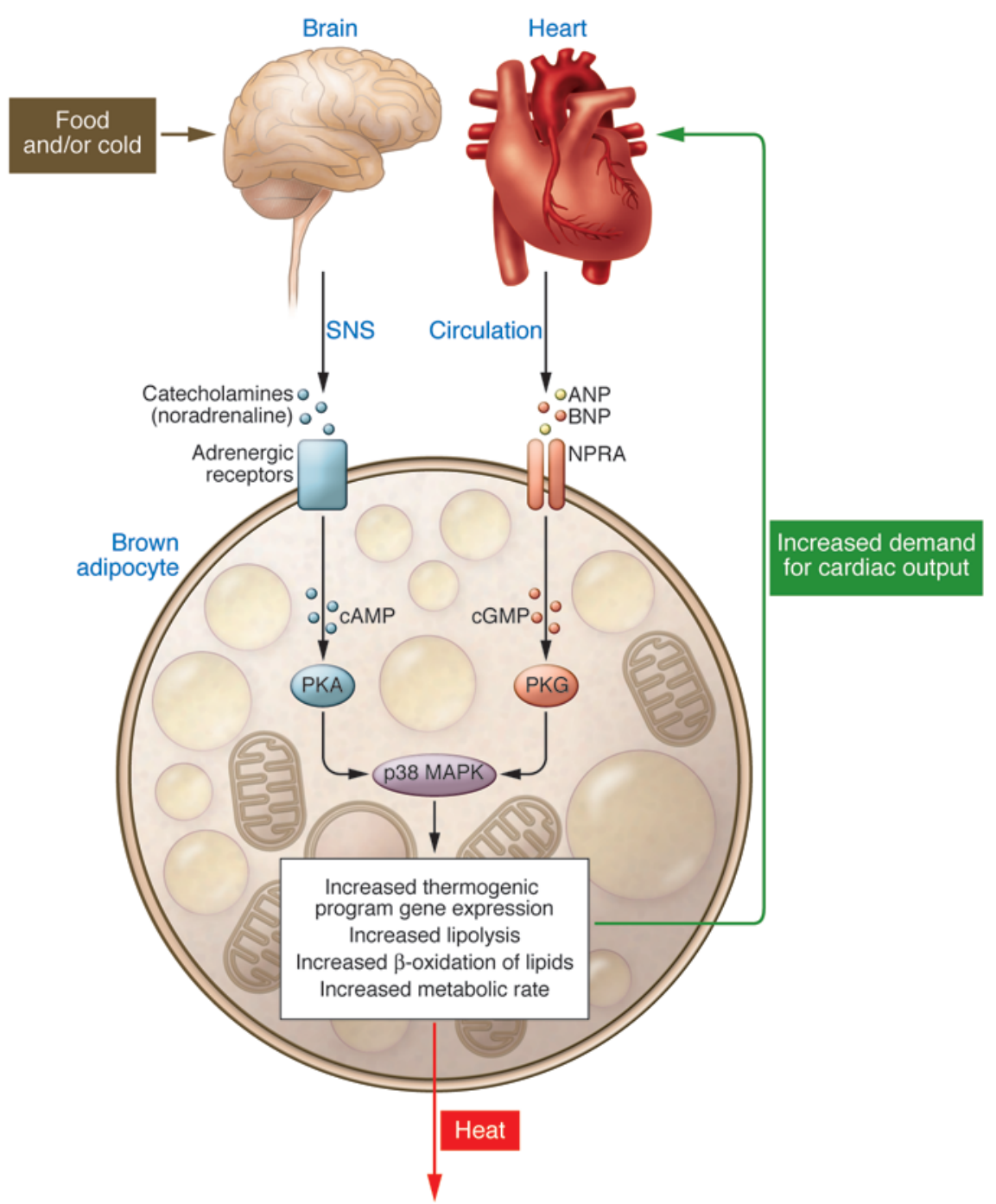

preadipocytes as they differentiate, again via increased p38 MAPK activation and induction of the thermogenic program (17). Other factors such as bile acids, which increase thyroid hormone signaling (18), and nitric oxide levels (19), which like NP increase cGMP levels, have also been shown to enhance the thermogenic program in brown adipocytes.

These developments seem to suggest that the p38 MAPK pathway exists as a physiological mechanism used by endogenous metabolic hormones and secretory molecules to "tap into" the adrenergic axis. BAT has a particular requirement for such mechanisms because it is a highly dynamic and plastic tissue. Adaptive alteration of their general level of sensitivity to adrenergic stimulation would confer greater flexibility to brown adipocytes. BAT would still respond to acute CNSinformed changes in thermogenic demand but would do so in the context of longerterm changes in environmental conditions (Figure 1). For instance, in response to a high calorie diet, thermogenesis increases due to alterations in SNS tone to BAT. The level of increase, though, is greater when animals are housed in cold environments (20). One might envisage, the effect of the dietary stimulus would be reduced at lower environmental temperatures, but this is not the case, demonstrating maintenance of acute responsiveness alongside a sustained increase in thermogenic activity (20). In support of this mechanism, Bordicchia et al. show that levels of circulating NP and expression of NPRA increase in BAT, while NPRC expression decreases following cold exposure (6). Of note, cardiac hypertrophy is a classical result of cold adaptation in rodents and may be a biological indicator for BAT to expand via increased NP signaling.

\section{Figure 1}

Hypothesized role of NPs as chronic regulators of BAT. Alterations in cardiac demand due to increased metabolic rate in a cold environment result in increased NP levels. NP signals via PKG to increase p38 MAPK and thus induce thermogenic machinery. As this bypasses the membrane adrenergic receptors and PKA, modulation of acute activity by the SNS is still possible but operates in the context of any chronic changes to basal thermogenic activity and capacity. A comparison could be made with a stereo system, where the volume dial is the adrenergic axis and the speaker size relates to the amount of $\mathrm{p} 38$ activation by other molecules such as NP. If the size of the speakers is increased tenfold, the stereo has a much higher maximum volume, but it is not necessary to turn the volume dial 10 more times to reach it.

\section{Potential for therapeutic activation of BAT}

The authors of the present study did not investigate the long-term effects of NP on energy balance or body weight. Nor did they administer NPs to mice that were already obese to assess their effectiveness as a weight loss strategy. Another important question that remains unanswered is whether NPs alter adrenergic sensitivity in other organs. If this is the case, it may render them as unfavorable as sibutramine or ephedrine for long-term use in humans.

However, the ability of NPs to modulate the effects of endogenous SNS activation in BAT makes them an exciting candidate for further investigation. In humans, we are beginning to understand that there is a negative correlation between BMI and fat mass and the detectability of active BAT (2). Thus, any molecule that was able to "trick" BAT into sensing its well-warmed human 
host was actually in a long-term cold environment may well have favorable bioenergetic effects in overweight individuals.

\section{Acknowledgments}

Andrew J. Whittle and Antonio VidalPuig are supported by the Biotechnology and Biological Sciences Research Council (BBSRC), the Medical Research Council (MRC), Wellcome Trust, and the European Commission (FP7 BetaBAT).

Address correspondence to: Antonio VidalPuig, University of Cambridge Metabolic Research Laboratories, Level 4, Institute of Metabolic Science, Box 289, Addenbrooke's Hospital, Cambridge CB2 0QQ, United Kingdom. Phone: 44.1223.762790; Fax: 44.1223.330598; E-mail: ajv22@cam.ac.uk.

1. Cypess AM, et al. Identification and importance of brown adipose tissue in adult humans. $N$ Engl J Med. 2009;360(15):1509-1517.

2. Ouellet V, et al. Outdoor temperature, age, sex, body mass index, and diabetic status determine the prevalence, mass, and glucose-uptake activity of 18F-FDG-detected BAT in humans. J Clin Endocrinol Metab. 2011;96(1):192-199.
3. Saito M, et al. High incidence of metabolically active brown adipose tissue in healthy adult humans: effects of cold exposure and adiposity. Diabetes. 2009;58(7):1526-1531.

4. Cannon B, Nedergaard J. Brown adipose tissue: function and physiological significance. Physiol Rev. 2004;84(1):277-359.

5. Seale $P$, et al. PRDM16 controls a brown fat/skeletal muscle switch. Nature. 2008;454(7207):961-967.

6 . Bordicchia $M$, et al. Cardiac natriuretic peptides act via p38 MAPK to induce the brown fat thermogenic program in mouse and human adipocytes. J Clin Invest. 2012;122(3):1022-1036.

7. Cao W, et al. p38 mitogen-activated protein kinase is the central regulator of cyclic AMP-dependent transcription of the brown fat uncoupling protein 1 gene. Mol Cell Biol. 2004;24(7):3057-3067.

8. Cao W, Medvedev AV, Daniel KW, Collins S. betaAdrenergic activation of $\mathrm{p} 38 \mathrm{MAP}$ kinase in adipocytes: cAMP induction of the uncoupling protein 1 (UCP1) gene requires p38 MAP kinase.J Biol Chem. 2001;276(29):27077-27082.

9. Astrup A, Lundsgaard C, Madsen J, Christensen NJ. Enhanced thermogenic responsiveness during chronic ephedrine treatment in man. Am J Clin Nutr. 1985;42(1):83-94

10. Finer N, Bloom SR, Frost GS, Banks LM, Griffiths $\mathrm{J}$. Sibutramine is effective for weight loss and diabetic control in obesity with type 2 diabetes: a randomised, double-blind, placebo-controlled study. Diabetes Obes Metab. 2000;2(2):105-112.

11. Haller CA, Benowitz NL. Adverse cardiovascular and central nervous system events associated with dietary supplements containing ephedra alkaloids.
N Engl J Med. 2000;343(25):1833-1838.

12. Torp-Pedersen $\mathrm{C}$, et al. Cardiovascular responses to weight management and sibutramine in highrisk subjects: an analysis from the SCOUT trial. Eur Heart J. 2007;28(23):2915-2923.

13. Misono KS. Natriuretic peptides and their receptors. FEBS J. 2011;278(11):1791.

14. Hondares E, Rosell M, Gonzalez FJ, Giralt M, Iglesias R, Villarroya F. Hepatic FGF21 expression is induced at birth via PPARalpha in response to milk intake and contributes to thermogenic activation of neonatal brown fat. Cell Metab. 2010; 11(3):206-212.

15. Ogawa Y, et al. BetaKlotho is required for metabolic activity of fibroblast growth factor 21. Proc Natl Acad Sci U S A. 2007;104(18):7432-7437.

16. Sellayah D, Bharaj P, Sikder D. Orexin is required for brown adipose tissue development, differentiation, and function. Cell Metab. 2011;14(4):478-490.

17. Tseng YH, et al. New role of bone morphogenetic protein 7 in brown adipogenesis and energy expenditure. Nature. 2008;454(7207):1000-1004.

18. Watanabe $\mathrm{M}$, et al. Bile acids induce energy expenditure by promoting intracellular thyroid hormone activation. Nature. 2006;439(7075):484-489.

19. Petrovic V, Buzadzic B, Korac A, Vasilijevic A Jankovic A, Korac B. NO modulates the molecular basis of rat interscapular brown adipose tissue thermogenesis. Comp Biochem Physiol C Toxicol Pharmacol. 2010;152(2):147-159.

20. Rothwell NJ, Stock MJ. Influence of environmental temperature on energy balance, diet-induced thermogenesis and brown fat activity in 'cafeteria'-fed rats. BrJ Nutr. 1986;56(1):123-129.

\title{
DYRK1A in Down syndrome: an oncogene or tumor suppressor?
}

\author{
Yehudit Birger ${ }^{1}$ and Shai Izraeli1,2 \\ ${ }^{1}$ Functional Genomics and Department of Pediatric Hemato-oncology, Edmond and Lily Safra Children's Hospital, Sheba Medical Center, \\ Tel Hashomer, Ramat Gan, Israel. ${ }^{2}$ Sackler Faculty of Medicine, Tel Aviv University, Tel Aviv, Israel.
}

\begin{abstract}
Children with Down syndrome (DS) have a markedly increased risk of developing acute megakaryoblastic leukemia (AMKL) and acute lymphoblastic leukemia compared with that of children without DS. Despite recent breakthroughs, it is not clear which genes on chromosome 21, the chromosome that is trisomic in individuals with DS, cause this predisposition. In this issue of the JCI, Malinge et al. report their loss- and gain-of-function experiments in mouse and human cells that show that increased expression of the kinase encoded by the chromosome 21 gene DYRK1A suppresses the nuclear factor of activated $T$ cells pathway and promotes AMKL. Interestingly, the same protein has been suggested to contribute to the reduced risk of epithelial cancers in adults with DS, leading to the possibility that it could be proleukemic in children and antitumorigenic in adults.
\end{abstract}

Down syndrome (DS) is one of the most common genetic birth defects, affecting about 1 in 800 newborns a year in the

Conflict of interest: The authors have declared that no conflict of interest exists.

Citation for this article: J Clin Invest. 2012; 122(3):807-810. doi:10.1172/JCI62372.
United States. It is caused by constitutional trisomy 21 (cT21). The symptoms of DS are heterogeneous, ranging from mild to severe, as are the associated medical conditions. One of the associated medical conditions is leukemia - children with DS have a markedly higher risk of developing both acute lymphoblastic leukemia (ALL) and acute myeloid leukemia than do children who do not have DS. This is in sharp contrast with the reduced prevalence of epithelial cancers in adult individuals with DS (1). Thus, cT21 is proleukemogenic during the pediatric period but antitumorigenic in adulthood. In this issue of the JCI, Malinge et al. provide new insight into the functional contribution of trisomy 21 to leukemogenesis that may have therapeutic implications (2).

\section{DS-associated myeloid leukemias and the role of $\mathrm{cT} 21$}

DS-associated myeloid leukemias evolve in a unique, multistep clinical pattern (Figure 1 and reviewed in ref. 3). Epidemiologic studies have indicated that five percent of newborns with DS have transient myeloproliferative disorder (TMD), a condition that is characterized by the clonal expansion of immature megakaryo- 